\title{
Faktor yang Berhubungan dengan Penerimaan Alat Kontrasepsi dalam Rahim Pascasalin di Samarinda
}

\author{
Prima Deri Pella Todingbua' ${ }^{1}$, Ratnasari Dwi Cahyanti ${ }^{2}$, Supriyadi Hari Respati ${ }^{3}$, Eddy Hartono ${ }^{4}$ \\ ${ }^{1}$ RS A.W. Sjahranie, Samarinda \\ ${ }^{2}$ Bagian Obstetri dan Ginekologi, FK UNDIP \\ ${ }^{3}$ Bagian Obstetri dan Ginekologi, FK UNS \\ ${ }^{4}$ Bagian Obstetri dan Ginekologi, FK UNHAS \\ Korespondensi: obsgin.juli2015@gmail.com
}

Submisi: 16 Juni 2020; Revisi: 12 Juli 2020; Penerimaan: 20 Oktober 2020

\begin{abstract}
Background: Maternal mortality rate (MMR) in Indonesia is 305 per 100.000 live births. The intervention to suppress MMR according to four pillars of Safe Motherhood is reducing the possibility of woman becoming pregnant with Family Planning. The postpartum period is an important time to start, but underutilized. All contraceptive methods may be used, but the high rate of drop-out in non-long-term methods, counselling is directed to long-term methods like IUD.

Objective: To determine factor that related postpartum IUD acceptance in Samarinda.

Method: The research method is observational with cross sectional design. Sampling is done by purposive sampling. Data were obtained through questionnaire.

Result and Discussion: There was no significant association between age $(p=0.438)$, parity $(R R=0.7 ; p=0.077)$, education ( $R R=1.11$; $p=0.611)$, and income ( $R R=0.69 ; p=0.105)$ with acceptance of postpartum IUD. Employment ( $R R=1.64 ; p=0.025)$, history of family planning counselling ( $R R=3.37$; $p<0.001)$, and husband's approval ( $R R=28.8 ; p=<0.001)$ have significant association with the acceptance of postpartum IUD.

Conclusion: Age, parity, education, and income are not related factors of postpartum IUD acceptance, while employment, husband's approval, and history of family planning counselling are related factors of postpartum IUD acceptance in Samarinda.
\end{abstract}

Keywords: Postpartum IUD; family planning counselling; husband's approval

\begin{abstract}
ABSTRAK
Latar Belakang: Angka Kematian Ibu (AKI) di Indonesia sebesar 305 per 100.000 kelahiran. Salah satu bentuk intervensi untuk menekan AKI sesuai empat pilar Safe Motherhood adalah mengurangi kemungkinan perempuan menjadi hamil dengan Keluarga Berencana (KB). Periode pascasalin merupakan masa penting memulai kontrasepsi, namun kurang dimanfaatkan. Semua metode kontrasepsi dapat digunakan sebagai metode KB pascasalin, namun angka drop out (DO) yang tinggi dalam penggunaan non-Metode Kontrasepsi Jangka Panjang (MKJP), sehingga pelayanan konseling klien diarahkan untuk memilih MKJP seperti AKDR.

Tujuan: Untuk mengetahui faktor yang berhubungan dengan penerimaan AKDR pascasalin di Samarinda.

Metode: PMetode penelitian adalah observasional dengan desain cross sectional. Pengambilan sampel dengan menggunakan teknik purposive sampling. Data sampel diperoleh melalui kuesioner.

Hasil dan Pembahasan: 7Tidak ada hubungan signifikan antara usia $(p=0,438)$, paritas ( $R R=0,7 ; p=0,077)$, pendidikan $(R R=1,11 ; p=0,611)$, dan penghasilan ( $R R=0,69 ; p=0,105)$ dengan penerimaan AKDR pascasalin. Sedangkan pekerjaan $(R R=1,64 ; p=0,025)$, persetujuan suami $(R R=28,8$; $p=<0,001)$, dan riwayat konseling $K B(R R=3,37 ; p<0,001)$ memiliki hubungan dengan penerimaan AKDR pascasalin.

Kesimpulan: Usia, paritas, pendidikan, dan penghasilan tidak berhubungan dengan penerimaan AKDR pascasalin. Sedangkan pekerjaan, persetujuan suami, dan riwayat konseling KB berhubungan dengan penerimaan AKDR pascasalin di Samarinda.
\end{abstract}

Kata kunci: AKDR pascasalin; konseling KB; persetujuan suami 


\section{PENDAHULUAN}

Berdasarkan Survei Penduduk Antar Sensus (SUPAS) 2015, Angka Kematian Ibu (AKI) di Indonesia masih tinggi sebesar 305 per 100.000 kelahiran hidup. Target global Sustainable Development Goals (SDGs) kelima adalah menurunkan AKI menjadi 70 per 100.000 kelahiran hidup pada 2030. ${ }^{1}$ Kematian saat melahirkan menjadi faktor utama mortalitas perempuan pada masa puncak produktivitasnya. WHO memperkirakan terdapat 210 juta kehamilan setiap tahun di dunia. Salah satu bentuk intervensi untuk menekan AKI sesuai empat pilar upaya Safe Motherhood adalah mengurangi kemungkinan seorang perempuan menjadi hamil dengan upaya Keluarga Berencana (KB). ${ }^{2}$ Peran KB sangat penting karena dapat menekan angka kematian ibu dan bayi. Dengan perencanaan keluarga yang baik, kehamilan ibu diatur agar tidak terjadi di usia terlalu muda, terlalu tua, kehamilan terlalu rapat dan terlalu banyak. ${ }^{3}$

Di Samarinda, Kalimantan Timur, dengan jumlah penduduk 812.597 jiwa, menurut data tahun 2016 terdapat 138.565 Pasangan Usia Subur (PUS). Dari jumlah tersebut yang menjadi peserta KB adalah 93.873 (67,75\%) PUS. Dari jumlah PUS yang bukan peserta KB (44.692 PUS), sementara hamil 3.903, ingin anak segera 13.323 PUS, ingin anak ditunda 13.406 PUS, dan tidak ingin anak lagi sebanyak 14.108 PUS. $^{4}$

Periode pascasalin merupakan masa yang penting untuk memulai kontrasepsi, namun masih kurang dimanfaatkan. Banyak hal yang berkontribusi terhadap kehamilan yang tidak diinginkan, meliputi kurangnya pengetahuan pasien, metode kontrasepsi yang tidak efektif, penggunaan kontrasepsi yang tidak konsisten, aktivitas seksual yang tidak direncanakan, dan kegagalan kontrasepsi. Dari beberapa faktor di atas yang sifatnya tergantung individu pasien, konseling KB merupakan faktor yang berada dalam ranah para klinisi. ${ }^{5}$

Walaupun semua metode kontrasepsi dapat digunakan sebagai metode KB pascasalin, namun mengingat angka drop out (DO) yang cukup tinggi dalam penggunaan non Metode Kontrasepsi Jangka Panjang (MKJP), maka dalam memberikan pelayanan konseling klien diarahkan untuk memilih MKJP, seperti implan dan AKDR. ${ }^{3}$ Berdasarkan laporan BKKBN Kaltim, disebutkan bahwa penerima AKDR Pascasalin di Kalimantan Timur pada tahun 2016 berjumlah 3.317 dari 609.981 PUS $(0,005 \%)$.
Mengingat rendahnya angka penerimaan AKDR Pascasalin di Kalimantan Timur, khususnya Samarinda, maka penulis tertarik untuk mengetahui faktor yang berhubungan dengan penerimaan AKDR pascasalin di Samarinda.

\section{METODE}

Metode penelitian yang dipakai dalam penelitian ini adalah observasional dengan desain cross sectional. Subyek penelitian adalah semua perempuan pascasalin di rumah sakit umum, rumah sakit bersalin, klinik bidan, dan puskesmas di Samarinda. Pengambilan sampel dilakukan sejak Desember 2017 sampai Februari 2018.

Variabel tergantung penelitian ini adalah penerimaan AKDR pascasalin, sedangkan variabel bebas nya adalah usia, paritas, pendidikan, pekerjaan, penghasilan, persetujuan keluarga (suami), dan riwayat konseling KB saat ANC.

Analisis bivariat menggunakan uji statistik dengan metode chi square. Analisis multivariat menggunakan uji statistik dengan metode regresi logistik.

\section{HASIL DAN PEMBAHASAN}

Tabel 1 Karakteristik Subyek Penelitian Perempuan Pascasalin

\begin{tabular}{|c|c|c|c|}
\hline \multicolumn{2}{|c|}{ Variabel } & $\mathbf{N}$ & $\%$ \\
\hline \multirow{5}{*}{ Usia } & Menerima & 62 & 40,0 \\
\hline & Menolak & 93 & 60,0 \\
\hline & $<20$ tahun & 12 & 7,7 \\
\hline & 20-35 tahun & 113 & 72,9 \\
\hline & $>35$ tahun & 30 & 19,4 \\
\hline \multirow{2}{*}{ Paritas } & Tinggi $^{1}$ & 57 & 36,8 \\
\hline & Rendah ${ }^{2}$ & 98 & 63,2 \\
\hline \multirow{2}{*}{ Pendidikan } & Tinggi $^{3}$ & 111 & 71,6 \\
\hline & Rendah $^{4}$ & 44 & 28,4 \\
\hline \multirow{2}{*}{ Pekerjaan } & Bekerja & 27 & 17,4 \\
\hline & Tidak Bekerja & 128 & 82,6 \\
\hline \multirow{2}{*}{ Penghasilan } & Cukup5 & 127 & 81,9 \\
\hline & Rendah6 & 28 & 18,1 \\
\hline \multirow{2}{*}{ Persetujuan Suami } & Setuju & 79 & 51,0 \\
\hline & Tidak Setuju & 76 & 49,0 \\
\hline \multirow{2}{*}{$\begin{array}{l}\text { Riwayat Konseling } \\
\text { KB }\end{array}$} & Pernah & 94 & 60,6 \\
\hline & Tidak Pernah & 61 & 39,4 \\
\hline
\end{tabular}


Jumlah subyek adalah 155 orang, terdiri dari 62 subyek kelompok menerima AKDR dan 93 subyek kelompok tidak menerima AKDR. Karakteristik subyek tersebut diperlihatkan pada tabel 1.

Pada Tabel 1 memperlihatkan perempuan pascasalin kelompok menerima AKDR pascasalin (40\%) dan menolak AKDR pascasalin (60\%) secara umum sebagian besar sampel berusia 20-35 tahun (72,9\%), mempunyai paritas $1-2$ anak $(63,2 \%)$, berpendidikan tinggi $(71,6 \%)$, berpenghasilan cukup $(81,9 \%)$, tidak berkerja (82,6\%), mendapat persetujuan suami (51,0\%), dan riwayat konseling KB sebelumnya $(60,6 \%)$.

Tabel 2 Hasil Analisis Univariat

\begin{tabular}{|c|c|c|c|c|c|c|}
\hline \multirow{2}{*}{ Variabel } & \multicolumn{2}{|c|}{ Menerima AKDR Pascasalin } & \multicolumn{2}{|c|}{ Tidak Menerima AKDR Pascasalin } & \multicolumn{2}{|c|}{ Total } \\
\hline & $n$ & (\%) & $n$ & (\%) & $\mathbf{N}$ & (\%) \\
\hline \multicolumn{7}{|l|}{ Usia } \\
\hline$<20$ tahun & 4 & $33,3 \%$ & 8 & $66,7 \%$ & 12 & $100 \%$ \\
\hline $20-35$ tahun & 43 & $38,1 \%$ & 70 & $61,9 \%$ & 113 & $100 \%$ \\
\hline$>35$ tahun & 15 & $50,0 \%$ & 15 & $50,0 \%$ & 30 & $100 \%$ \\
\hline \multicolumn{7}{|l|}{ Paritas } \\
\hline Tinggi & 28 & $34,7 \%$ & 29 & $65,3 \%$ & 57 & $100 \%$ \\
\hline Rendah & 34 & $49,1 \%$ & 64 & $50,9 \%$ & 98 & $100 \%$ \\
\hline \multicolumn{7}{|l|}{ Pendidikan } \\
\hline Tinggi & 43 & $43,2 \%$ & 68 & $56,8 \%$ & 111 & $100 \%$ \\
\hline Rendah & 19 & $38,7 \%$ & 25 & $61,3 \%$ & 44 & $100 \%$ \\
\hline \multicolumn{7}{|l|}{ Pekerjaan } \\
\hline Bekerja & 16 & $59,3 \%$ & 11 & $40,7 \%$ & 27 & $100 \%$ \\
\hline Tidak Bekerja & 46 & $35,9 \%$ & 82 & $64,1 \%$ & 128 & $100 \%$ \\
\hline \multicolumn{7}{|l|}{ Penghasilan } \\
\hline Cukup & 47 & $37,0 \%$ & 80 & $63,0 \%$ & 127 & $100 \%$ \\
\hline Rendah & 15 & $53,6 \%$ & 13 & $46,4 \%$ & 28 & $100 \%$ \\
\hline \multicolumn{7}{|c|}{ Persetujuan Suami } \\
\hline Ya & 60 & $75,9 \%$ & 19 & $24,1 \%$ & 79 & $100 \%$ \\
\hline Tidak & 2 & $2,6 \%$ & 74 & $97,4 \%$ & 76 & $100 \%$ \\
\hline \multicolumn{7}{|c|}{ Riwayat Konseling KB } \\
\hline Ya & 52 & $55,3 \%$ & 42 & $44,7 \%$ & 94 & $100 \%$ \\
\hline Tidak & 10 & $16,4 \%$ & 51 & $83,6 \%$ & 61 & $100 \%$ \\
\hline
\end{tabular}

Tabel 2 menunjukkan distribusi frekuensi tergantung pada sampel penelitian. masing-masing variabel bebas terhadap variabel 
Tabel 3 Hasil Analisis Bivariat

\begin{tabular}{|c|c|c|c|c|c|c|c|}
\hline \multirow[t]{2}{*}{ Variabel } & \multicolumn{2}{|c|}{$\begin{array}{c}\text { Menerima AKDR } \\
\text { Pascasalin }\end{array}$} & \multicolumn{2}{|c|}{$\begin{array}{c}\text { Tidak Menerima AKDR } \\
\text { Pascasalin }\end{array}$} & \multirow[t]{2}{*}{$\mathbf{R R}$} & \multirow[t]{2}{*}{$95 \% \mathrm{Cl}$} & \multirow[t]{2}{*}{$\mathbf{P}$} \\
\hline & $\mathbf{N}$ & $(\%)$ & $\mathbf{N}$ & (\%) & & & \\
\hline \multicolumn{8}{|l|}{ Usia } \\
\hline $20-35$ tahun & 43 & 38,1 & 70 & 61,9 & 1,18 & $0,79-1,78$ & 0,417 \\
\hline$<20 ;>35$ tahun & 19 & 45,2 & 23 & 54,8 & & & \\
\hline \multicolumn{8}{|l|}{ Paritas } \\
\hline Tinggi & 28 & 34,7 & 29 & 65,3 & 0,70 & $0,48-1,03$ & 0,077 \\
\hline Rendah & 34 & 49,1 & 64 & 50,9 & & & \\
\hline \multicolumn{8}{|l|}{ Pendidikan } \\
\hline Tinggi & 43 & 43,2 & 68 & 56,8 & 1,11 & $0,73-1,68$ & 0,611 \\
\hline Rendah & 19 & 38,7 & 25 & 61,3 & & & \\
\hline \multicolumn{8}{|l|}{ Pekerjaan } \\
\hline Bekerja & 16 & 59,3 & 11 & 40,7 & 1,64 & $1,11-2,43$ & $0,025^{*}$ \\
\hline Tidak Bekerja & 46 & 35,9 & 82 & 64,1 & & & \\
\hline \multicolumn{8}{|l|}{ Penghasilan } \\
\hline Cukup & 47 & 37,0 & 80 & 63,0 & 0,69 & $0,45-1,04$ & 0,105 \\
\hline Rendah & 15 & 53,6 & 13 & 46,4 & & & \\
\hline \multicolumn{8}{|c|}{ Persetujuan Suami } \\
\hline Ya & 60 & 75,9 & 19 & 24,1 & 28,8 & $7,31-113,9$ & $<0,001 *$ \\
\hline Tidak & 2 & 2,6 & 74 & 97,4 & & & \\
\hline \multicolumn{8}{|c|}{ Riwayat Konseling KB } \\
\hline Ya & 52 & 55,3 & 42 & 44,7 & 3,37 & $1,86-6,11$ & $<0,001 *$ \\
\hline Tidak & 10 & 16,4 & 51 & 83,6 & & & \\
\hline
\end{tabular}

*signifikansi $p<0,05$

Tabel 4 Analisis Multivariat

\begin{tabular}{lcccc}
\multirow{2}{*}{ Kelompok } & RR & \multicolumn{2}{c}{$95 \% \mathbf{C l}$} & P \\
\cline { 3 - 4 } & & Lower & Upper & \\
Pekerjaan & 1,73 & 0,41 & 7,13 & 0,232 \\
Persetujuan Suami & 113,14 & 24,18 & 529,33 & $<0,001^{*}$ \\
Riwayat Konseling KB & 5,77 & 1,92 & 17,32 & 0,002 \\
\hline
\end{tabular}

Tabel 3 menunjukkan bahwa usia tidak memiliki hubungan yang signifikan dengan penerimaan AKDR pascasalin $(p=0,417)$. Paritas juga tidak menunjukkan hubungan yang signifikan dengan penerimaan AKDR pascasalin $(p=0,077)$. Pendidikan tidak memiliki hubungan signifikan dengan penerimaan AKDR pascasalin $(p=0,611)$. Penghasilan juga tidak memiliki hubungan signifikan dengan penerimaan AKDR pascasalin $(p=0,105)$.
Sedangkan hubungan signifikan dapat terlihat antara pekerjaan dengan penerimaan AKDR pascasalin $(p=0,025)$. Persetujuan suami juga menunjukkan hubungan yang sangat signifikan dengan penerimaan AKDR pascasalin $(p<0,001)$. Begitu pula pada riwayat konseling KB sebelumnya juga menunjukkan hubungan yang sangat signifikan dengan penerimaan AKDR pascasalin $(p<0,001)$. 
Berdasarkan Tabel 4 tersebut terlihat bahwa variabel bebas yang memenuhi kriteria dalam pemodelan multivariat adalah pekerjaan, persetujuan suami, dan riwayat konseling KB. Analisis multivariat menyatakan persetujuan suami $(p=<0,001)$ dan riwayat konseling $K B(p=0,002)$ memiliki hubungan dengan penerimaan $A K D R$ pascasalin. Sedangkan pekerjaan $(p=0,232)$ tidak memiliki hubungan dengan penerimaan AKDR pascasalin. Menurut analisis multivariat tersebut didapatkan bahwa faktor yang paling berhubungan dengan penerimaan AKDR pascasalin adalah subyek dengan persetujuan suami ( $R R=113,1495 \% \mathrm{Cl}$ : 26,83-803,02).

Usia sangat erat hubungannya dengan pengetahuan seseorang karena dengan semakin bertambahnya usia, maka semakin banyak juga pengetahuannya. ${ }^{7}$ Faktor usia sangat berpengaruh, dimana untuk Pasangan Usia Subur (PUS) yang usia dibawah 20 tahun dianjurkan menunda kehamilan dengan menggunakan pil KB, suntik, susuk, kondom. Sedangkan PUS yang berusia 20-35 tahun dianjurkan mengatur jarak kehamilan dengan menggunakan suntik, susuk, AKDR. Kemudian PUS yang berusia di atas 35 tahun atau pada fase mengakhiri kesuburan dianjurkan menggunakan kontrasepsi mantap. ${ }^{8}$

Kemudian pada penelitian ini didapatkan paritas tidak memiliki hubungan dengan penerimaan AKDR pascasalin dengan nilai $p=0,077$ dan $R R=0,70(95 \% \mathrm{Cl}$ : $0,48-1,03)$. Hasil tersebut sesuai dengan penelitian di Tomohon yang menyatakan bahwa tidak ada hubungan antara paritas dengan penggunaan AKDR dengan nilai $p=0,704$ dan $R R=0,70 .{ }^{9}$ Begitu juga dengan penelitian di India dan di Turki dimana wanita dengan paritas satu sampai dua cenderung lebih menerima kontrasepsi pascasalin, namun tidak bermakna, dibandingkan wanita dengan paritas lebih dari dua. ${ }^{10}$

Penelitian ini juga menyatakan pendidikan tidak memiliki hubungan yang signifikan dengan penerimaan AKDR pascasalin dengan nilai $p=0,611$ dan $\mathrm{RR}=1,11$ (95\% Cl: 0,73-1,68). Subyek yang menerima AKDR pascasalin dan tidak menerima AKDR pascasalin relatif sama didapatkan lebih banyak pada kelompok pendidikan tinggi. Hal ini kemungkinan dipengaruhi oleh program wajib belajar yang ditetapkan di Indonesia adalah 12 tahun (hingga tamat SMA), sehingga banyak subyek dari penelitian yang berasal dari kelompok tersebut. Hasil tersebut sesuai dengan penelitian di Turki yang menyatakan pendidikan tidak memiliki hubungan dengan penerimaan AKDR pascasalin dengan nilai $p=0,109$ dan $R R=2,747 .{ }^{11}$ Semakin tinggi tingkat pendidikan ibu akan menambah pengetahuan ibu dalam pemilihan alat kontrasepsi yang cocok untuk dirinya. Ini disebabkan seseorang yang berpendidikan tinggi akan lebih luas pandangannya dan lebih mudah menerima ide dan tata cara kehidupan yang baru, termasuk pentingnya keikutsertaan dalam pemilihan alat kontrasepsi. ${ }^{12}$

Kemudian penelitian ini menyatakan pekerjaan memiliki hubungan yang bermakna dengan penerimaan AKDR pascasalin dengan nilai $p=0,025$ dan $\mathrm{RR}=1,64$ (95\% Cl: 1,11-2,43). Penelitian di Manado juga menyatakan bahwa pada penerima AKDR maupun bukan penerima AKDR relatif sama besar ditemukan pada kelompok yang tidak berkerja, sehingga pekerjaan tidak memiliki hubungan dengan penggunaan AKDR dengan nilai $p=0,202 .{ }^{13}$

Lingkungan pekerjaan dapat membuat seseorang memperoleh pengalaman dan pengetahuan yang lebih banyak dan luas, baik secara langsung maupun tidak langsung. Dengan kondisi sebagai seorang pegawai atau seorang karyawan, seorang ibu diharapkan dapat memilih metode kontrasepsi yang memiliki efektivitas tinggi dan bertahan jangka lama seperti AKDR sehingga dapat membantu ibu lebih nyaman dalam bekerja. ${ }^{14}$

Menurut penelitian ini penghasilan tidak memiliki hubungan yang bermakna dengan penerimaan AKDR pascasalin dengan nilai $p=0,105$ dan $\mathrm{RR}=0,69$ (95\% Cl: 0,45-1,04). Subyek yang menerima AKDR pascasalin dan tidak menerima AKDR pascasalin relatif sama didapatkan lebih banyak pada kelompok penghasilan cukup. Hal ini kemungkinan dipengaruhi oleh pendapatan keluarga termasuk suami yang bekerja sehingga menambah penghasilan keluarga. Penelitian lain juga menyatakan tidak ada hubungan antara penghasilan dengan penerimaan AKDR pascasalin dengan nilai $p=0,100 \cdot{ }^{15}$

Sedangkan persetujuan suami, penelitian ini menyatakan persetujuan suami memiliki hubungan yang bermakna dengan penerimaan AKDR pascasalin 
dengan nilai $p=<0,001$ dan $R R=28,86$ (95\% Cl: 7,31113,93). Hasil ini sesuai dengan penelitian lain yang menyatakan persetujuan suami memiliki hubungan dengan penggunaan AKDR dengan nilai $p=0,005$ dan $R R=11,05 .{ }^{9}$ Dukungan suami sebagai motivator merupakan salah satu faktor yang sangat berpengaruh dan memiliki hubungan yang bermakna terhadap pemilihan AKDR pascasalin. Faktor dukungan suami dapat dikatakan sebagai salah satu faktor yang memungkinkan suatu motivasi atau aspirasi terlaksana. ${ }^{16}$

Penelitian ini menunjukkan bahwa riwayat konseling sebelumnya juga berpengaruh positif terhadap penerimaan AKDR pascasalin dengan nilai $p=<0,001$ dan $R R=3,37$ (95\% Cl: 1,8-6,11). Penelitian lain di Turki juga menyatakan terdapat hubungan antara riwayat konseling $\mathrm{KB}$ dengan penerimaan AKDR pascasalin dengan nilai $p=0,035$ dan $\mathrm{RR}=7,984 .{ }^{11}$ Penelitian lain juga menyatakan bahwa riwayat konseling sebelumnya memiliki hubungan dengan penerimaan AKDR pascasalin dengan nilai $\mathrm{p}=0,001$ dan $\mathrm{RR}=3,118 .{ }^{17}$

Konseling merupakan aspek yang penting dalam pelayanan KB. Dengan melakukan konseling berarti petugas membantu klien dalam memilih dan memutuskan jenis kontrasepsi yang digunakan sesuai dengan pilihannya. ${ }^{18}$ Dengan konseling yang diberikan lagi saat persalinan kemungkinan ibu akan memulai KB secara lebih dini. ${ }^{19}$

\section{KESIMPULAN DAN SARAN}

Pada penelitian ini didapatkan bahwa persetujuan suami, riwayat konseling $K B$, dan pekerjaan berhubungan dengan penerimaan AKDR pascasalin. Sedangkan umur, paritas, pendidikan dan penghasilan tidak berhubungan dengan penerimaan AKDR pascasalin di Samarinda.

\section{DAFTAR PUSTAKA}

1. Kementerian Kesehatan Republik Indonesia. 2014. Pusat Data dan Informasi Kementerian Kesehatan Republik Indonesia. Diakses 5 Oktober 2017 dari Kementerian Kesehatan Republik Indonesia: http:// www.depkes.go.id/resources/download/pusdatin/ infodatin/infodatin-ibu.pdf
2. Saifuddin, A.B. 2011. Upaya Safe Motherhood dan Making Pregnancy Safer dalam Bunga Rampai Obstetri dan Ginekologi Sosial. Jakarta: PT Bina Pustaka Sarwono Prawirohardjo.

3. Budisuari, M. A., \& Rachmawati, T. 2011. Analisis Pengembangan Kebijakan Keluarga Berencana di Jawa Timur, Bali dan Kalimantan Tengah. Surabaya: Badan Penelitian Kesehatan. Vol.14. 90-101.

4. Badan Pusat Statistik Provinsi Kalimantan Timur. 2017. Badan Pusat Statistik Provinsi Kalimantan Timur. Diakses 1 Oktober 2017 dari Badan Pusat Statistik Provinsi Kalimantan Timur: http://kaltim. bps.go.id/

5. Cowman, W., Hardy-Fairbanks, A., Endres, J., dan Stockdale, CK. 2013. A Select Issue In The Postpartum Period: Contraception The Importance Of Providing Postpartum Contraception Counseling. Proceedings in Obstetrics and Gynecology. 3(2): 1-15.

6. Mujiati, I. 2013. Pelayanan KB Pasca Persalinan Dalam Upaya Mendukung Percepatan Penurunan Angka Kematian Ibu. Buletin Jendela Data dan Informasi Kesehatan. 2:11 - 16.

7. Notoatmodjo, S. 2007. Promosi Kesehatan dan IImu Perilaku. Jakarta: Rineka Cipta.

8. Wiknjosastro, Hanifa. 2010. Ilmu Kandungan. Jakarta: Yayasan Bina Pustaka Sarwono Prawirohardjo

9. Frisca, L., Meiske R., \& Iyem M. 2013. FaktorFaktor Yang Berhubungan Dengan Penggunaan Alat Kontrasepsi Dalam Rahim (AKDR) Di Kelurahan Pangolombian Kota Tomohon Tahun 2013. Jidan. Vol.I. 46-50

10. Maluchuru, S., \& Aruna, V. 2015. Post partumintrauterine device insertion-2yr experience at a tertiary care center in guntur medical college govt general hospital. Journal of Dental and Medical Sciences Ver. IV , 2279-2861.

11. Yilmazel, G., \& Balci, E. 2013. Preferences and related factors for postpartum contraception in pregnant women. Iran J of Reprod Med, 801-806.

12. Kusumaningrum R. 2009. Faktor-Faktor Yang Mempengaruhi Pemilihan Jenis Kontrasepsi Yang Digunakan Pada Pasangan Usia Subur. Semarang.: FK. Universitas Diponegoro.

13. Roeroe Lingkan R, Kondou Grace D, \& Ratag E. Gustaaf. 2013. Faktor-Faktor yang Berhubungan dengan Tindakan Akseptor Keluarga Berencana (KB) dalam Memilih Alat Kontrasepsi Dalam Rahim (AKDR) di BLU RSUP Prof Kandou Malalayang Manado. Manado. Jurnal Kedokteran Komunitas dan Tropik. 1: 29-33

14. Mubarak, WI. 2012. Ilmu Kesehatan Masyarakat Konsep dan Aplikasi dalam Kebidanan. Jakarta : Salemba Medika. 
15. Handayani, Desmiwati, \& Endrinaldi. 2013. Faktorfaktor yang Berhubungan Dengan Unmet Need KB Pasca-Salin IUD post-placenta di Kamar Rawat Pascabersalin RSUP DR. M. Djamil periode Januari-Maret 2013. Padang. Universitas Andalas.

16. Handayani, S. 2010. Buku Ajar Pelayanan Keluarga Berencana. Yogyakarta: Pustaka Rihama.

17. Sopiatun, Ekayani \& Chandradewi. 2013. Pengaruh Pemberian Konseling Keluarga Berencana (KB) terhadap Alat Kontrasepsi IUD Post Plasenta di RSUP NTB Tahun 2013. Mataram. IPSDI. 7(5): 7-12
18. Saifuddin, A.B. 2013. Konseling dan Persetujuan Tindakan Medis: Buku Panduan Praktis Pelayanan Kontrasepsi. Edisi 3. Jakarta: Yayasan Bina Pustaka Sarwono Prawirohardjo.

19. Abbas, Marwan. 2016. Pengaruh Konseling Saat Persalinan Terhadap Kepesertaan Keluarga Berencana Pasca Salin di Kabupaten Kolaka. Yogyakarta: Universitas Gadjah Mada 